OPEN ACCESS

Edited by:

Pankaj,

University of Edinburgh,

United Kingdom

Reviewed by:

Shuqiao Xie,

Imperial College London,

United Kingdom

Giulia Brunello,

University Hospital of Düsseldorf,

Germany

*Correspondence:

Sara Checa

sara.checa@bih-charite.de

${ }^{\text {t}}$ These authors share last authorship

Specialty section:

This article was submitted to

Biomechanics,

a section of the journal

Frontiers in Bioengineering and

Biotechnology

Received: 27 October 2021 Accepted: 29 December 2021

Published: 10 February 2022

Citation:

Orassi V, Fischer H, Duda GN,

Heiland $M$, Checa $S$ and

Rendenbach C (2022) In Silico

Biomechanical Evaluation of WE43

Magnesium Plates for Mandibular

Fracture Fixation.

Front. Bioeng. Biotechnol. 9:803103.

doi: 10.3389/fbioe.2021.803103

\section{In Silico Biomechanical Evaluation of WE43 Magnesium Plates for Mandibular Fracture Fixation}

\author{
Vincenzo Orassi ${ }^{1,2}$, Heilwig Fischer ${ }^{3}$, Georg N. Duda ${ }^{1}$, Max Heiland $^{3}$, Sara Checa ${ }^{1 * t}$ and \\ Carsten Rendenbach ${ }^{3+}$
}

${ }^{1}$ Berlin Institute of Health at Charité-Universitätsmedizin Berlin, Julius Wolff Institute, Berlin, Germany, ${ }^{2}$ Berlin-Brandenburg School for Regenerative Therapies, Berlin, Germany, ${ }^{3}$ Department of Oral and Maxillofacial Surgery, Charité-Universitätsmedizin Berlin, Corporate Member of Freie Universität Berlin, Humboldt-Universität zu Berlin and Berlin Institute of Health, Berlin, Germany

Titanium fixation devices are the gold standard for the treatment of mandibular fractures; however, they present serious limitations, such as non-degradability and generation of imaging artifacts. As an alternative, biodegradable magnesium alloys have lately drawn attention due to their biodegradability and biocompatibility. In addition, magnesium alloys offer a relatively high modulus of elasticity in comparison to biodegradable polymers, being a potential option to substitute titanium in highly loaded anatomical areas, such as the mandible. This study aimed to evaluate the biomechanical competence of magnesium alloy WE43 plates for mandibular fracture fixation in comparison to the clinical standard or even softer polymer solutions. A 3D finite element model of the human mandible was developed, and four different fracture scenarios were simulated, together with physiological post-operative loading and boundary conditions. In a systematic comparison, the material properties of titanium alloy Ti-6Al-4V, magnesium alloy WE43, and polylactic acid (PLA) were assigned to the fixation devices, and two different plate thicknesses were tested. No failure was predicted in the fixation devices for any of the tested materials. Moreover, the magnesium and titanium fixation devices induced a similar amount of strain within the healing regions. On the other hand, the PLA devices led to higher mechanical strains within the healing region. Plate thickness only slightly influenced the primary fixation stability. Therefore, magnesium alloy WE43 fixation devices seem to provide a suitable biomechanical environment to support mandibular fracture healing in the early stages of bone healing. Magnesium WE43 showed a biomechanical performance similar to clinically used titanium devices with the added advantages of biodegradability and radiopacity, and at the same time it showed a remarkably higher primary stability compared to PLA fixation devices, which appear to be too unstable, especially in the posterior and more loaded mandibular fracture cases.

Keywords: finite element, mechanobiology, biomechanics, magnesium WE43, biodegradable, osteosynthesis 


\section{INTRODUCTION}

The therapeutic gold standard for the treatment of simple mandibular fractures is open reduction and internal fixation with titanium miniplates and screws. Titanium alloys like Ti$6 \mathrm{Al}-4 \mathrm{~V}$ are biocompatible, are resistant to corrosion, and provide high mechanical strength (Riviş et al., 2020). However, the use of titanium is associated with several drawbacks. The latter includes the induction of metal imaging artifacts in computed tomography, cone beam computed tomography, and magnetic resonance imaging (Radzi et al., 2014; Rendenbach et al., 2018; Demirturk Kocasarac et al., 2019), which reduces the diagnostic quality, e.g., in identifying malignancies and additional pathologies or to assess the progress of healing. Due to the rather high stiffness of such plate constructs, the undesired stress-shielding effect in load-bearing implants cannot be excluded and may impact union or induce even non-unions (Viljanen et al., 1995). Once the healing process is completed and implants are no longer functional (Rosa et al., 2016), their presence might interfere with facial growth (in adolescents), increase the infection risk, or be a source of metallic ion release (Katou et al., 1996; Armencea et al., 2019; Wang et al., 2019). Furthermore, when positioned in close proximity to the mental nerve, chronic pain and paraesthesia can result (Hachleitner et al., 2014). These considerations lead to the general strategy of plate removal in up to $70 \%$ of all cases, including both symptomatic and asymptomatic plates (Matthew and Frame, 1999; Bhatt et al., 2005; Van Bakelen et al., 2013; Sukegawa et al., 2020).

To overcome these challenges in metal plate fixation, alternative biomaterials for such implants, with more advantageous mechanical and biological features, have been considered. To date, mainly polymeric biodegradable options, such as polylactic acid (PLA) and composites thereof, have been tested in fracture fixation. PLA-based fixation devices have been proven to be effective in promoting bone healing in head and neck reconstructive surgeries (Suuronen et al., 1998; Sukegawa et al., 2016) and, generally, in minimally loaded anatomical locations (Moe and Weisman, 2001; Lee et al., 2010). However, concerns about the biomechanical reliability of PLAbased fixation systems in regions of high loadings, such as in the mandible, still remain. In fact, due to their low elastic modulus, these materials often lack sufficient primary fixation stability (Shetty et al., 1997; Buijs et al., 2006; Van Bakelen et al., 2013), and their use is generally limited to load-sharing indications in selected patients (Wang et al., 2016; On et al., 2020).

Alternatively, magnesium-based fixation systems have been long studied, thanks to their excellent biocompatibility and osteogenic properties (Witte et al., 2005), radiopacity, and a favorable elastic modulus closer to that of the human cortical bone than titanium. Nevertheless, the clinical use of magnesium in fracture fixation was not possible for many years due to its high reactivity in vivo, resulting in rapid hydrogen gas formation in bone and soft tissues during degradation by corrosion and, consequently, wound healing disorders and fixation failure (Witte, 2010). Recently, however, less reactive alloys, like
WE43, and, more importantly, surface modification via plasma electrolytic oxidation (PEO) (Arrabal et al., 2008; Simchen et al., 2020; Hartjen et al., 2021; Rendenbach et al., 2021) have been introduced. In particular, PEO-coated WE43 alloy showed improved cytocompatibility, cell viability, and corrosion resistance compared to the corresponding non-coated alloys (Hartjen et al., 2021). Therefore, magnesium regained relevance for clinical use in load-bearing applications of reconstructive and trauma surgery. Several in vivo preclinical studies successfully observed new bone deposition around WE43 plates and screws (Schaller et al., 2016; Naujokat et al., 2017; Byun et al., 2020; Imwinkelried et al., 2020; On et al., 2020; Rendenbach et al., 2021; Torroni et al., 2021) and a preserved structural integrity in the first 12 weeks of the healing process (Marukawa et al., 2016; Levorova et al., 2018). However, to date, only Leonhardt et al. (Leonhardt et al., 2017; Leonhardt et al., 2021) reported a clinical application of magnesium-based lag screws for mandibular condylar head fracture fixation. No plate fixation of a midfacial or mandibular fracture has been performed in humans so far. Therefore, it remains unknown if WE43 fixation plates can provide sufficient mechanical primary stability for mandibular fracture healing.

This study aimed to investigate whether the fixation stability provided by magnesium alloy WE43 devices results in considerable changes in the biomechanical environment within mandibular fractures in comparison to the goldstandard titanium and alternative polylactide-based devices in the early stages of the healing process. A computational model of the human mandible was developed, and different fracture scenarios were simulated in association with variations in the design and material properties of the fixation devices. An evaluation of the biomechanical performance of biodegradable magnesium alloy WE43 versus traditional titanium alloy $\mathrm{Ti}-6 \mathrm{Al}-4 \mathrm{~V}$ and biodegradable PLA was performed in terms of both assessment of implant failure risk and quantification of the biomechanical strain provided at the healing site.

\section{MATERIALS AND METHODS}

\section{Finite Element Models}

A cone-beam computed tomography (CBCT) scan of a human skull of a 20-year-old male individual was performed in axial mode, with a voxel size of $0.4 \mathrm{~mm}^{3}$ (ProMax, Planmeca, Finland). Material segmentation of the fully dentate mandible was performed in the software Amira 6.0.1 (Zuse Institute Berlin, Germany), labeling cortical and trabecular bone tissues. Thereafter, a 3D linear tetrahedral mesh (element type C3D4) was created. The finite element model was then imported into the commercial software Abaqus/CAE v.6.18 (Dassault Systèmes Simulia Corp., United States), where the linear mesh was converted into a quadratic mesh with element type C3D10. Here four different simple fractures of approximately $1.5-1.2 \mathrm{~mm}$ width were simulated in the mandibular symphysis, body, angle, and condylar neck regions, respectively, as shown in Figure 1.

The fixation devices were designed in the 3D-CAD software SolidWorks 2019 (Dassault Systèmes, France) based on 

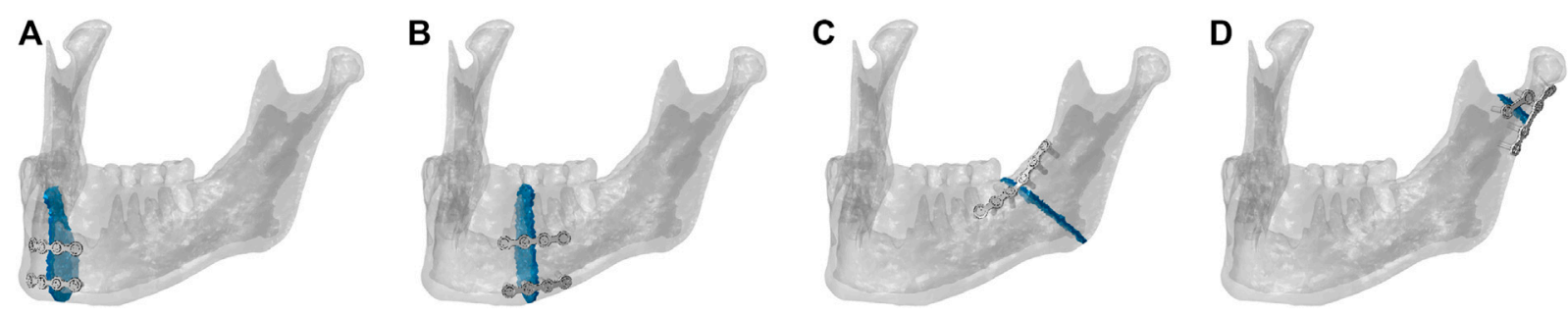

FIGURE 1 | Mandibular fracture scenarios: mandibular (A) symphysis, (B) body, (C) angle, and (D) condylar neck fractures and corresponding osteosynthesis devices. The healing region is highlighted in blue.

TABLE 1 | Orthotropic and isotropic material properties assigned to the mandibular bone tissues, fracture volume, and implants.

\begin{tabular}{|c|c|c|c|c|c|c|c|c|c|c|c|c|}
\hline $\begin{array}{l}\text { Material } \\
\text { properties }\end{array}$ & Symphysis & Body & Angle & Ramus & Condyle & $\begin{array}{l}\text { Coronoid } \\
\text { process }\end{array}$ & $\begin{array}{c}\text { Trabecular } \\
\text { bone }\end{array}$ & Teeth & $\begin{array}{l}\text { Granulation } \\
\text { tissue }\end{array}$ & Ti-6Al-4V & WE43 & PLA \\
\hline E1 & 20,492 & 21,728 & 23,793 & 24,607 & 23,500 & 28,000 & 300 & 17,600 & 3 & 110,000 & 44,200 & 3,500 \\
\hline E2 & 16,350 & 17,828 & 19,014 & 18,357 & 17,850 & 17,500 & 300 & 17,600 & 3 & 110,000 & 44,200 & 3,500 \\
\hline E3 & 12,092 & 12,700 & 12,757 & 12,971 & 12,650 & 14,000 & 300 & 17,600 & 3 & 110,000 & 44,200 & 3,500 \\
\hline$v 12$ & 0.34 & 0.34 & 0.3 & 0.28 & 0.24 & 0.23 & 0.3 & 0.34 & 0.4 & 0.34 & 0.27 & 0.36 \\
\hline$v 23$ & 0.22 & 0.2 & 0.22 & 0.23 & 0.25 & 0.28 & 0.3 & 0.34 & 0.4 & 0.34 & 0.27 & 0.36 \\
\hline$v 13$ & 0.43 & 0.45 & 0.41 & 0.38 & 0.32 & 0.28 & 0.3 & 0.34 & 0.4 & 0.34 & 0.27 & 0.36 \\
\hline G12 & 6,908 & 7,450 & 7,579 & 7,407 & 7,150 & 7,150 & - & 6,567 & 1 & 41,045 & 17,000 & 1,287 \\
\hline G23 & 4,825 & 5,083 & 4,986 & 5,014 & 5,150 & 5,300 & - & 6,567 & 1 & 41,045 & 17,000 & 1,287 \\
\hline G13 & 5,317 & 5,533 & 5,493 & 5,386 & 5,500 & 5,750 & - & 6,567 & 1 & 41,045 & 17,000 & 1,287 \\
\hline
\end{tabular}

E, elastic modulus (MPa); v, Poisson's ratio (-); G, shear modulus (MPa); direction 1, longitudinal or axial; direction 2, tangential; direction 3, transverse.

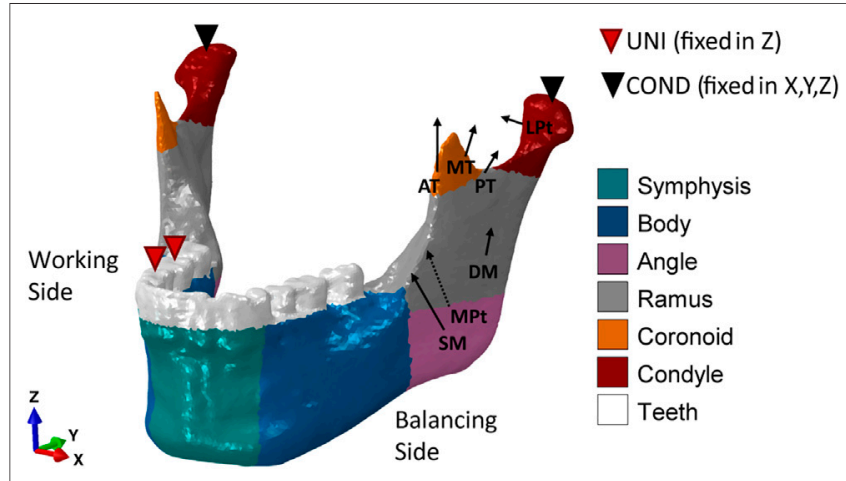

FIGURE 2 | Loading and boundary conditions for the healthy human mandible during unilateral (UNI) clenching. Bite force was simulated by restraining the vertical displacement at the occlusion and both condyles in the 6 degrees of freedom. During UNI clenching, the right and the left mandibular bodies are considered as the working side and the balancing side, respectively. The cortical bone was subdivided into six regions to which different orthotropic properties were assigned (Table 1).

commercially available devices. Two different miniplate thicknesses were tested: 1-mm-thick clinically used miniplates versus alternative 1.5-mm-thick miniplates, in combination with simplified (without thread) monocortical 7-mm-long screws. The plates were adapted to the mandibular bone surfaces and positioned according to the four fracture scenarios (Figure 1). For the same fracture case, accurate overlapping of the $1-\mathrm{mm}$ - and $1.5-\mathrm{mm}$-thick miniplates was achieved to exclude possible influences of plate positioning on the results. As shown in Figure 1, according to the principles of Champy et al. (1978) and the guidelines of AO Foundation ORIF (2021a) and followed by clinical advice, fracture fixation was performed with 2.0 miniplate systems. Specifically, two parallel 4hole miniplates were used in the mandibular symphysis (AO Foundation ORIF, 2021d) and body regions (AO Foundation ORIF, 2021c). In the mandibular angle region, a 6-hole miniplate and, in the mandibular condylar neck region, a 2- and a 4-hole miniplate, both with a center space (AO Foundation ORIF, 2021b), were used. The devices were imported into Abaqus and meshed with a quadratic mesh (element type C3D10). Thereafter, tie constraints were applied between plates and screws and between screws and mandibular bone tissues.

\section{Material Properties}

All material properties are reported in Table 1. Orthotropic material properties were assigned to the cortical bone, identifying six different regions according to Schwartz-Dabney and Dechow (2003) and Lovald et al. (2009) (Figure 2). Isotropic material properties were assigned to the trabecular bone (Lakatos et al., 2014), the teeth region (Lovald et al., 2009), and the fracture tissue volumes (Lovald et al., 2009), modeled as granulation tissue to simulate the early stage of bone healing.

Three different material properties were assigned to the osteosynthesis devices: traditional titanium alloy Ti-6Al-4V (Lovald et al., 2009), magnesium alloy WE43 (MatWeb, 2021), and PLA (Torres et al., 2015). To define the elastic working regions of every material, the yield strength of titanium, magnesium, and PLA was assumed equal to $880 \mathrm{MPa}$ 
TABLE 2|Force, direction cosines, and activation patterns of muscle groups for unilateral clenching in the human mandible. The muscular force components (Fx, Fy, and Fz) were obtained by multiplying the post-operative force magnitude [reduced to $20 \%$ of the maximum muscle force calculated by Nelson (1986)] by the direction cosines and the fiber activation value for both working and balancing sides (Korioth et al., 1992).

\begin{tabular}{|c|c|c|c|c|c|c|c|c|}
\hline \multirow{3}{*}{$\begin{array}{l}\text { Mandibular muscle } \\
\text { group }\end{array}$} & \multirow{3}{*}{$\begin{array}{c}\text { Maximum } \\
\text { muscle force (N) }\end{array}$} & \multirow{3}{*}{$\begin{array}{l}\text { Post-operative } \\
\text { muscle force (N) }\end{array}$} & \multicolumn{4}{|c|}{ Direction cosine } & \multicolumn{2}{|c|}{ Fiber activation } \\
\hline & & & \multicolumn{2}{|c|}{$x$} & \multirow[t]{2}{*}{$\mathbf{Y}$} & \multirow[t]{2}{*}{$\mathbf{Z}$} & \multirow{2}{*}{$\begin{array}{l}\text { Working side } \\
\text { (right) }\end{array}$} & \multirow{2}{*}{$\begin{array}{c}\text { Balancing side } \\
\text { (left) }\end{array}$} \\
\hline & & & Right & Left & & & & \\
\hline Superficial masseter & 190.4 & 38.08 & -0.207 & 0.207 & -0.419 & 0.884 & 0.72 & 0.60 \\
\hline Deep masseter & 81.6 & 16.32 & -0.546 & 0.546 & 0.358 & 0.758 & 0.72 & 0.60 \\
\hline Anterior temporalis & 158.0 & 31.6 & -0.149 & 0.149 & -0.044 & 0.988 & 0.73 & 0.58 \\
\hline Medial temporalis & 95.6 & 19.12 & -0.222 & 0.222 & 0.500 & 0.837 & 0.66 & 0.67 \\
\hline Posterior temporalis & 75.6 & 15.12 & -0.208 & 0.208 & 0.855 & 0.474 & 0.59 & 0.39 \\
\hline Medial pterygoid & 174.8 & 34.96 & 0.486 & -0.486 & -0.373 & 0.791 & 0.84 & 0.60 \\
\hline Lateral pterygoid & 66.9 & 13.38 & 0.630 & -0.630 & -0.757 & -0.174 & 0.30 & 0.65 \\
\hline
\end{tabular}

$X Y$, transverse plane; $Y Z$, sagittal plane; $X Z$, coronal plane.
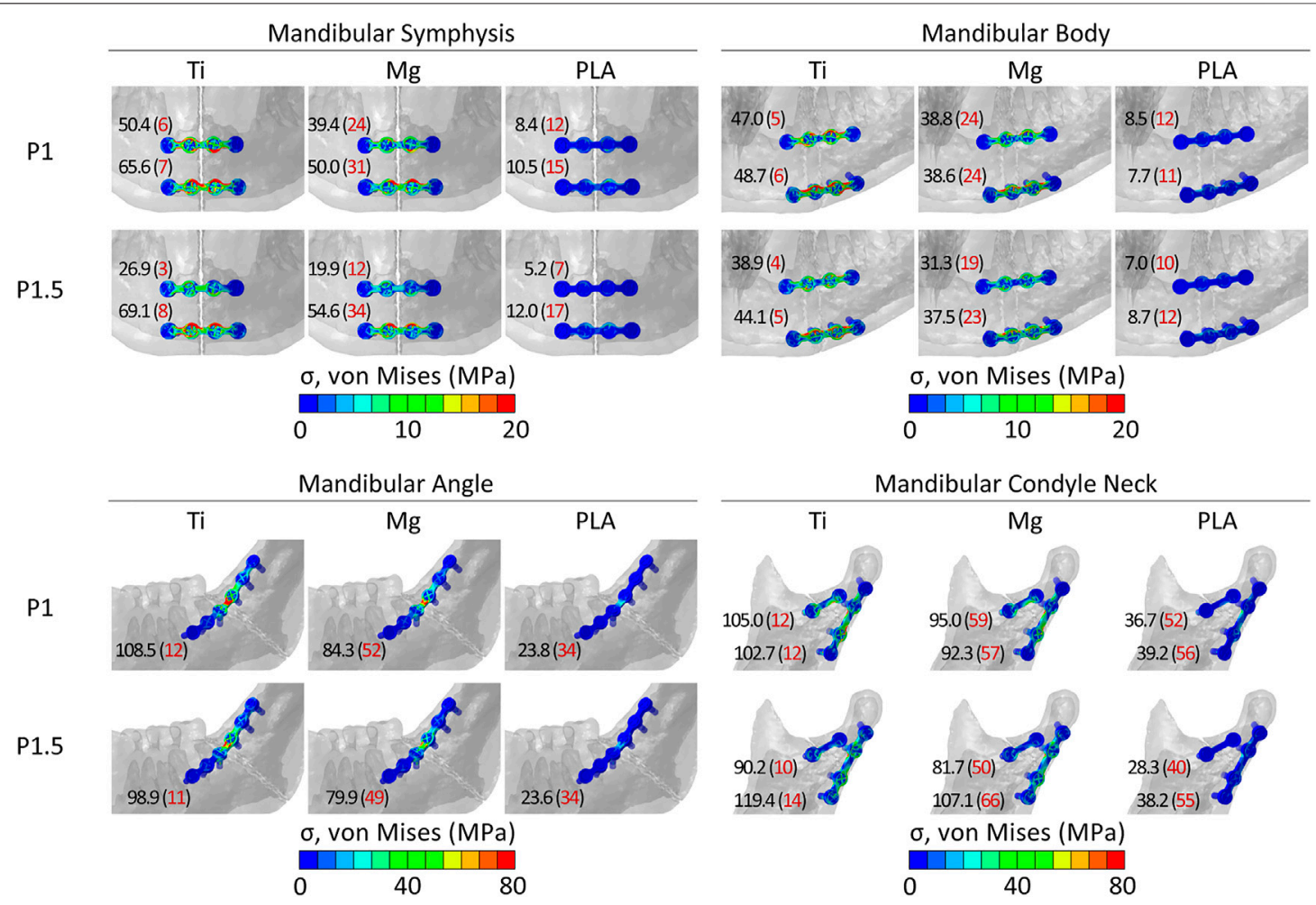

FIGURE 3 |Distribution and peak values of von Mises stress within the implants in the four fracture scenarios. In red, in brackets, peak values as a percentage of the

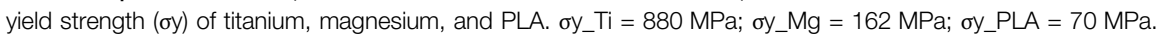

(MatWeb, 2021), $162 \mathrm{MPa}$ (MatWeb, 2021), and $70 \mathrm{MPa}$ (Torres et al., 2015), respectively.

\section{Loading and Boundary Conditions}

Several studies found that contralateral molar occlusion induced the highest amount of mechanical solicitation and therefore could represent a critical clenching task (Korioth et al., 1992; Lovald et al., 2009; Hijazi et al., 2016). Therefore, unilateral clenching was chosen as the only and worst clenching task to be tested in this study. Specifically, right unilateral clenching was simulated by restraining the vertical displacement of the first molar-second premolar teeth group (Figure 2). At the power stroke of mastication, the condyles were assumed locked in the glenoid fossa and therefore restrained in all 6 degrees of freedom.

Post-operative loading conditions were applied by simulating the contraction of superficial masseter (SM), deep masseter (DM), anterior temporalis (AT), medial temporalis (MT), posterior temporalis (PT), medial pterygoid (MPt), and inferior lateral pterygoid (LPt) muscles (Figure 2). The magnitude of the muscular forces was reduced to $20 \%$ of the maximum muscle forces as reported by Nelson (1986) to adapt it to post-operative muscle forces (Table 2). The muscle fiber activation patterns for 
unilateral clenching used in this study have been described by Nelson (1986), while the directions of the force vectors are based on Korioth et al. (1992).

\section{Mesh Convergence Study}

Four different mesh sizes were used to perform a convergence study. Mesh (A) 1,099,247 elements (finest mesh), mesh (B) 645,150, mesh (C) 288,967 , and mesh (D) 168,784 (coarsest mesh) were tested. For this analysis, isotropic material properties were assigned to the bone tissues. Specifically, the elastic moduli of cortical and trabecular bone were chosen equal to 15,000 and $300 \mathrm{MPa}$, respectively, and a Poisson's ratio of 0.3 was defined (Orassi et al., 2021). The mesh creation workflow developed in this study only generates orphan meshes (without geometry). Therefore, to avoid variability between the four meshes in the definition of the muscular attachment areas, simplified and standardized loads were applied. Specifically, forces with components $\mathrm{Fx}=0, \mathrm{Fy}=-50 \mathrm{~N}$, and $\mathrm{Fz}=50 \mathrm{~N}$ were applied at the masseter attachment on a surface of $10-\mathrm{mm}$ radius during unilateral clenching. Average von Mises stresses and principal strains were calculated in the symphysis region and compared between the four cases. Mesh B, with element edges ca. $1 \mathrm{~mm}$ in length, showed the best compromise between accuracy and computational costs, with a relative error inferior to $5 \%$, and was, therefore, used in this study. Eventually, the same material properties used in this study were applied to mesh B, and the results were compared to the ones obtained from the isotropic model. Comparable outcomes were observed.

\section{Analysis}

The mechanical environment within the healing region is known to play a key role on the healing outcome. Claes and Heigele (1999) quantified strain levels lower than $15 \%$ in regions where bone formation takes place during the healing process. Therefore, the maximum and minimum principal strains within the four healing regions were calculated in all fracture scenarios for all combinations of plate thickness and material type. Specifically, the healing regions were defined as thin gaps across the bone (thickness of approximately $1.2 \mathrm{~mm}$ ) at the mandibular symphysis, body, angle, and condyle neck (Figure 1). Strains were computed at element integration nodes to avoid possible discontinuities of the strain field at the element edges. Moreover, at each integration node, only the largest, in absolute value, between the maximum and minimum principal strains was plotted to determine, respectively, the prevalent tensile or compressive solicitation of each specific node.

Similarly, von Mises stresses within plates and screws were calculated at the integration nodes. To avoid stress singularities due to constraints between plate and screws and between screws and bone, the top $0.1 \%$ highest von Mises stress values were excluded, and the peak von Mises stresses were calculated by averaging the values in the 10 nodes with the highest stress.

\section{RESULTS}

In the healthy mandible, a bite force of $100 \mathrm{~N}$ was obtained by calculating the reaction force at the occlusion during unilateral clenching.

\section{von Mises Stresses Within the Fixation Devices}

Concerning both plate thicknesses, the peak von Mises stresses never exceeded the yield strength of the materials. Titanium devices showed the best mechanical performance since the peak von Mises stresses ranged between 3 and $14 \%$ of titanium yield strength $(880 \mathrm{MPa})$. Higher peak stress values were found in PLA and magnesium, with the latter as the closest to its yield strength but with both still working in the elastic region. Specifically, in magnesium, the peak von Mises stresses were $12-66 \%$ of magnesium yield strength (162 MPa), while in PLA, the peak von Mises stresses were $7-56 \%$ of PLA yield strength $(70 \mathrm{MPa})$. Concerning the anatomical location, the highest mechanical solicitation of the fixation devices was predicted in mandibular angle and condyle neck fracture fixation (Figure 3).

\section{Influence of Fixation Material and Design on the Mechanical Strains Within the Healing Region}

Within the healing regions, titanium, magnesium, and PLA fixation devices induced overall tensile principal strains mainly between $0.5-1.8,0.7-3.2$, and $1.5-11.2 \%$, respectively, and the overall compressive strains were mainly between $0.4-3.7,0.7-4.1$, and $1.5-14.2 \%$, respectively (Figure 4).

In the case of fixation with 1-mm-thick titanium miniplates, most of the regenerating tissue volume was under strains between 0.5 and $3.7 \%$ (1st and 3rd quartiles). Similarly, $1-\mathrm{mm}$-thick magnesium miniplates induced mainly strains between 0.7 and $4.0 \%$, while 1 -mm-thick PLA miniplates induced mainly strains between 1.5 and $13.0 \%$ (Figure 4).

Small differences were predicted for an increment of miniplate thickness. Generally, the principal strains were comparable or slightly decreased using thicker plates; however, in the condyle neck fracture, both tensile and compressive strains induced by magnesium and PLA thicker plates increased. Specifically, compared to the corresponding 1-mm-thick plates, the magnesium 1.5-mm-thick plates induced tensile and compressive strains, respectively, 1 and $7 \%$ higher, while the PLA 1.5-mm-thick plates induced tensile and compressive strains, respectively, 4 and $9 \%$ higher.

\section{Influence of Fracture Location on the Mechanical Strains Within the Healing Region}

Figure 5 shows the distribution and magnitude of tensile and compressive strains within the healing region in the four fracture scenarios for all fixation designs. In the symphysis fracture, higher tensile and compressive strains were found at the inferior and crestal (top) sides, respectively, indicating mainly the bending of this region. In the body fracture, tensile and compressive strains were higher in the crestal-lingual and in the inferior-buccal sides, respectively, due to a combination of bending and torsional movements. In the angle fracture, tensile strains were mainly concentrated at the crestal side, while high compressive strains 


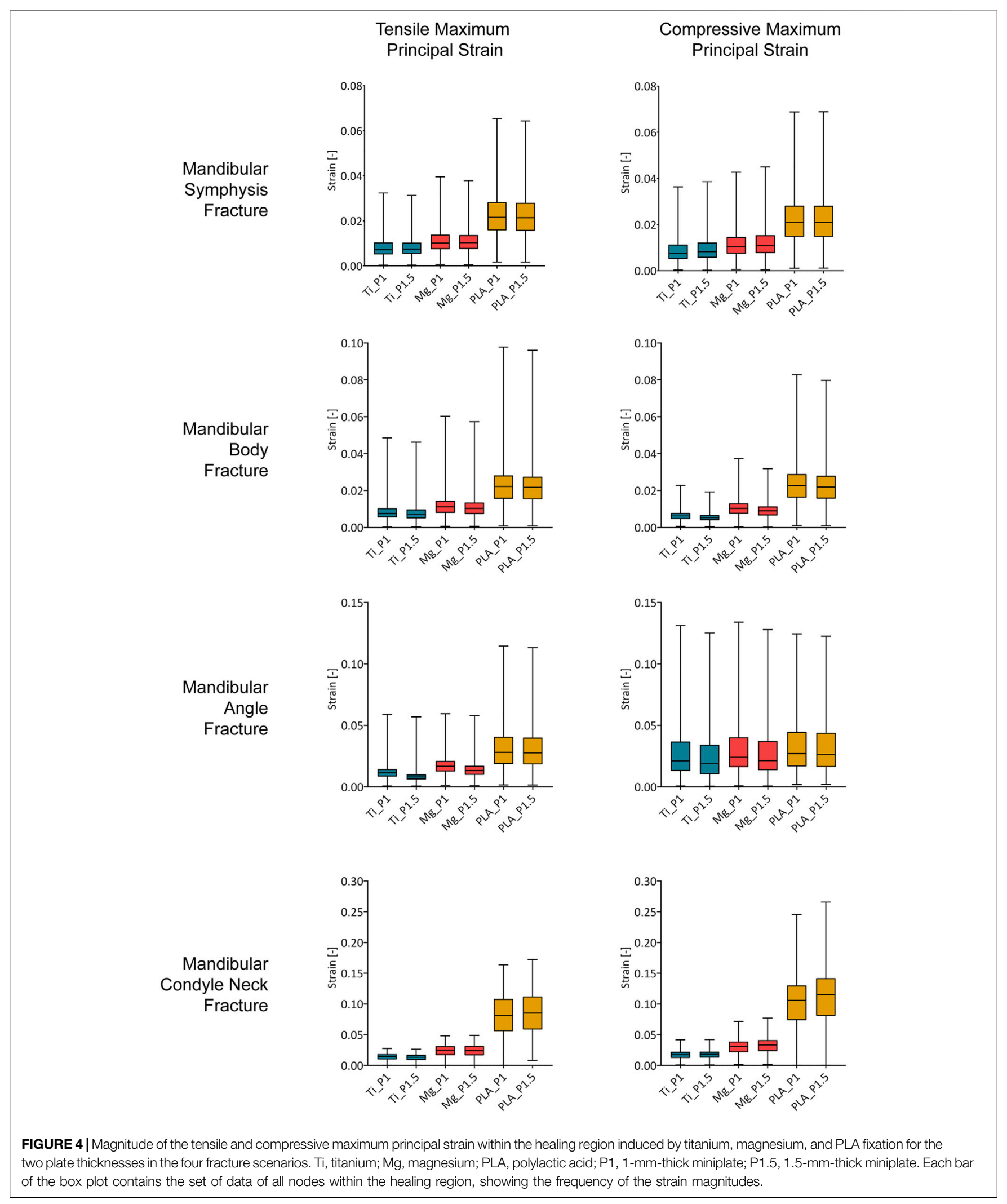




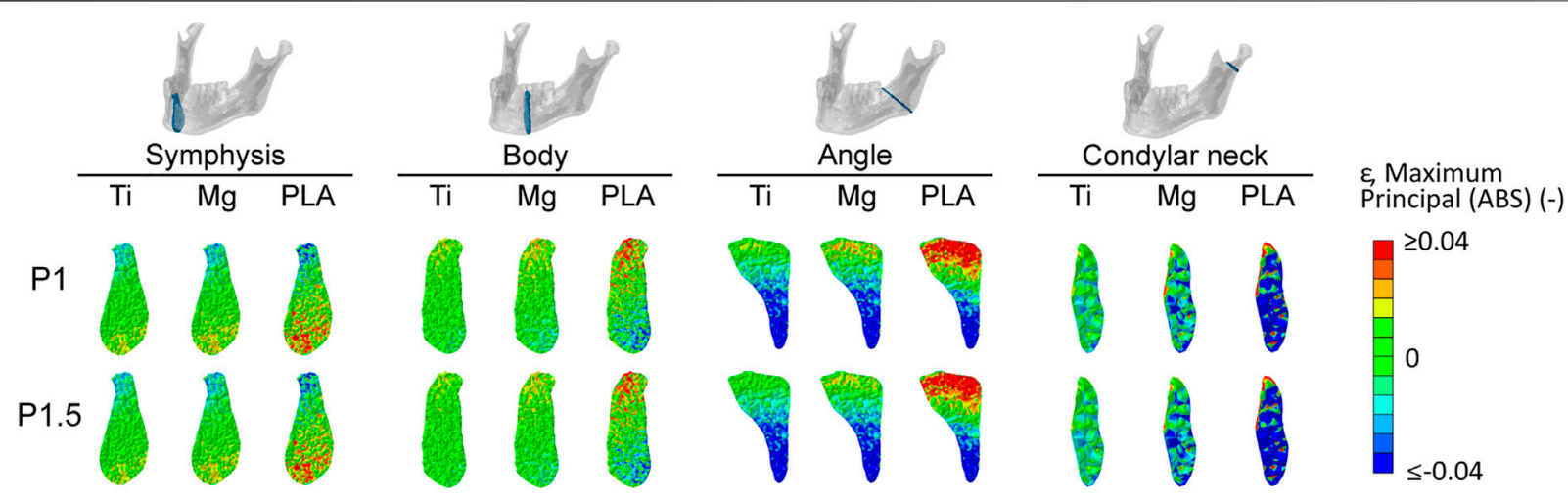

FIGURE 5 | Magnitude and distribution of the maximum principal strain within the healing region induced by titanium, magnesium, and PLA fixation for the two plate thicknesses in the four fracture scenarios. Positive and negative values indicate tensile and compressive strains, respectively. Ti, titanium; Mg, magnesium; PLA, polylactic acid; P1, 1-mm-thick miniplate; P1.5, 1.5-mm-thick miniplate.

were calculated at the inferior side of the healing region due to a prevalent bending movement. In the condylar neck fracture, high tensile strains were localized at the superior border, while high compressive strains were calculated in the whole region, indicating compression and relative sliding of the fracture ends.

Regarding both mandibular symphysis and body fractures, most of the volume of the healing region (first and third quartile) (Figure 4) showed tensile and compressive strains between 0.4 and $2.9 \%$. In the posterior fractures, the majority of the fracture volume was characterized by higher strains. Specifically, in the mandibular angle fracture, tensile values between 0.6 and $4.1 \%$ and compressive values between 1.0 and $4.5 \%$ were predicted, while in the mandibular condylar neck fracture, tensile values between 0.9 and $11.2 \%$ and compressive values between 1.2 and $14.2 \%$ were predicted.

\section{DISCUSSION}

In this study, the biomechanical performance of mandibular fracture fixation with magnesium WE43 plates and screws was evaluated by finite element analysis. In particular, muscle forces were reduced consistently to a post-operative bite force (Gerlach and Schwarz, 2002) to simulate the biomechanical conditions during the early stages of fracture healing. Moreover, four fracture scenarios were simulated according to the most common fractured areas in the mandible (Kaura et al., 2018) and fixated with osteosynthesis devices in traditional titanium alloy and biodegradable magnesium alloy WE43 and PLA. As compensation for the lower mechanical properties of the biodegradable materials, two miniplate thicknesses, clinically used 1-mm-thick and increased 1.5 -mm-thick miniplates, were tested, both in combination with monocortical 7-mm-long screws. Subsequently, the influence of the different biomaterials and plate thicknesses on the mechanical strains within the healing region immediately after surgery (a time point known to play a role on bone healing outcome) was investigated. The results show that WE43 magnesium seems to be a suitable candidate for mandibular fracture fixation in terms of both mechanical resistance and biomechanical conditions provided at the fracture site.

The peak von Mises stresses within the fixation devices suggest that all three materials can mechanically sustain the loads in the four case scenarios without incurring a structural failure. The ratio between the peak von Mises stress and yield strength for the magnesium devices was less favorable than in the case of titanium and PLA devices; however, the predicted stresses place the WE43 magnesium alloy behavior still in the elastic region in a postoperative bite force scenario. Surprisingly, in the condylar neck region, the stress values indicate that PLA devices can withstand the masticatory loads, although they remarkably lowered the fixation stiffness.

The predicted strains in the healing regions show that metallic implants, i.e., titanium and magnesium, generally provided higher fixation stiffness compared to the polylactide implants. In particular, the difference between metallic and PLA implants was marked in the mandibular angle and condylar neck fractures, where the closeness to the muscle force application points translated into higher strains within the healing regions at both locations with PLA devices, as also found in other studies (Jung et al., 2020; Park et al., 2020). The good overlapping of the strain ranges induced by titanium and magnesium fixation devices suggests that, despite having an elastic modulus of less than half of titanium, magnesium alloy WE43 seems to ensure sufficient fixation in all tested fracture scenarios. In particular, magnesium devices also performed similarly to titanium in the more loaded posterior fractures, while PLA devices induced remarkably higher mechanical strains within the healing region, which might lead to a different healing response in vivo (e.g., delayed union).

Furthermore, the observed differences in the strain magnitudes between the four fracture scenarios suggest that, anteriorly (mandibular symphysis and body), bone healing happens at lower mechanical strains, while posteriorly (mandibular angle and condyles), where the muscle forces are applied, bone healing happens at higher strains. This is consistent with previous computer model predictions (Tams et al., 1999; Lovald et al., 2009; Kimsal et al., 2011). Interestingly, in this study, 
the calculated overall mechanical strains at the fracture sites induced by clinically used titanium devices $(-4 \div 2 \%)$ are in the same range of strain values beneficial for bone healing in long bones $(|\varepsilon|<15 \%)$ (Claes and Heigele, 1999). This suggests a similar mechano-regulation of bone healing between mandibular bone and long bones; however, this needs to be further investigated.

While changes in the implant material properties proved to highly influence fixation stiffness, according to this study, a 0.5 $\mathrm{mm}$ increase of plate thickness did not substantially influence either the mechanical solicitation of the devices or the biomechanical environment within the healing region. Specifically, at the mandibular body and angle fractures, a relatively small reduction of the strain level was predicted by increasing the thickness. Interestingly, at the condyle neck fracture, increased plate thickness induced slightly increased strains, using magnesium and PLA devices. The reason for this must be found in the combination of the plate thickness and material properties of the devices at this specific location. In fact, increasing the plate thickness led to a reduction of the peak von Mises stress in the 2-hole miniplate and an increase of the stresses in the 4-hole miniplate. This, in combination with the reduced stiffness of the biodegradable devices and the high torsional forces at the condylar region, determined a different and slightly higher mechanical solicitation of the healing region. To assess a possible influence of screw penetration within the bone tissues, an increased screw length ( $7.5 \mathrm{~mm}$ in length), in combination with the 1.5 -mm-thick miniplates in mandibular symphysis, body, and angle fractures, was also tested, but no substantial differences in the strain values at the fracture site were induced by the longer screws (supplementary data).

The finite element model developed in this study is based on a previous finite element study of the healthy mandible (Orassi et al., 2021), which, in a maximum bite force condition, showed strain magnitudes and distribution that are in good agreement with previous computer studies (Korioth et al., 1992; Baek et al., 2012). Specifically, Korioth et al. (1992) found tensile and compressive strains of ca. 250 and $-400 \mu \varepsilon$ in the condylar neck, similar to ours, and of ca. 600 and $-500 \mu \varepsilon$ in the body region, slightly higher than the ones predicted in this study (400 and $-300 \mu \varepsilon)$. However, as shown by Baek et al. (2012), a high variability $(>100 \%)$ of mandibular deformation can be expected between mandibles with different morphological features. In addition, in this study, in the mandibular body fracture, fixated with two parallel, 1-mm-thick titanium miniplates and a bite force of $100 \mathrm{~N}$ (20\% of the maximum bite force), average maximum strain values of ca. $0.6-0.8 \%$ and a peak von Mises stress of 47-49 MPa were predicted. This is in agreement with the results found by Lovald et al. (2009), who simulated a mandibular body fracture fixated with two parallel titanium miniplates with a bite force of $320 \mathrm{~N}(60 \%$ of the maximum bite force). They observed average first principal strain values within the healing regions of ca. $1.7 \%$ and a peak von Mises stress of $87 \mathrm{MPa}$ within the plates. Therefore, our results are consistent with the analysis performed by Lovald et al. (2009), considering that, in this study, a third of their bite force was used and small differences might exist in terms of the mandibular morphology and plate design and positioning.
This study presents several limitations-for example, fixation device material properties were defined as isotropic, homogeneous, and elastic. PLA viscoelastic behavior was not taken into account; however, cycling loading during mastication might contribute to increasing the deformation of the PLA fixation devices cycle after cycle (Pepelnjak et al., 2020), thus further reducing the primary stability at the fracture site. This implies that, in reality, PLA might provide less stability than the one predicted in our study. Another limitation of this study is the use of tie constraints for screw-bone interface modeling, which does not allow the relative motion between screws and bone that might occur in reality. However, this limitation is unlikely to influence our findings since, as also shown in another study (MacLeod et al., 2012), only the local mechanical environment in the surroundings of the screws is affected, while the global load-displacement behavior of the model remains unvaried. Moreover, the analysis did not take into account the WE43 alloy and PLA degradation process. PEO-coated magnesium WE43 has been shown to maintain up to ca. $80 \%$ of its volume at 6 months after implantation (Schaller et al., 2016), and PLAbased devices can preserve up to $70 \%$ of their initial mechanical strength after 36 weeks (Wang et al., 2016). Complete bone healing in mandibular fractures can take up to 6 months; however, functional loading is progressively restored starting from the fourth week after surgery (Friedman, 2014). Therefore, it is expected that material degradation does not highly interfere with the healing process, and it should not influence the conclusions drawn in this study due to slow degradation rates for both materials (Yerit et al., 2005; Rendenbach et al., 2021); however, this aspect remains to be further investigated.

In summary, this study aimed to investigate the biomechanical performance of magnesium WE43 alloy in mandibular fracture fixation in contrast with both clinically used titanium and softer biodegradable PLA devices. From a mechanical point of view, magnesium WE43 alloy was predicted to provide sufficient primary stiffness at the fracture site to support mandibular bone healing. The effect of plate and screw resorption on the healing process should be addressed in future studies.

\section{DATA AVAILABILITY STATEMENT}

The datasets presented in this article are not readily available because they present some patented elements. Requests to access the datasets should be directed to SC, sara.checa@ bih-charite.de.

\section{AUTHOR CONTRIBUTIONS}

$\mathrm{VO}, \mathrm{CR}, \mathrm{GD}, \mathrm{MH}$, and SC designed the study. HF performed the CBCT and the anatomical observations. VO developed the computational models and collected the data. VO and SC interpreted the data and drafted the manuscript. All authors read and revised the manuscript and approved its content. 


\section{ACKNOWLEDGMENTS}

The authors acknowledge the support of European Union (EU) Horizon 2020 for the project InterLynk (grant agreement: H2020NMBP-TR-IND-2020, project ID: 953169).

\section{REFERENCES}

AO Foundation ORIF (2021a). AO Foundation Mandible. Available at: https:// surgeryreference.aofoundation.org/cmf/trauma/mandible (Accessed December 15, 2021a).

AO Foundation ORIF (2021b). Two Load Sharing Plates for Symphysis and Parasymphysis - Simple. Available at: https://surgeryreference.aofoundation. org/cmf/trauma/mandible/symphysis-and-parasymphysis-simple/orif-two-loadsharing-plates (Accessed December 15, 2021b)

AO Foundation ORIF (2021c). Two Load Sharing Plates for Body - Simple. Available at: https://surgeryreference.aofoundation.org/cmf/trauma/ mandible/body-simple/orif-two-load-sharing-plates\#examples-of-completedosteosynthesis (Accessed December 15, 2021c).

AO Foundation ORIF (2021d). Plate Fixation with Two Plates for Condylar Process and Head - Simple and Complex. Available at: https:// surgeryreference.aofoundation.org/cmf/trauma/mandible/condylar-processand-head-simple-and-complex/orif-plate-fixation-two-plates (Accessed December 15, 2021d).

Armencea, G., Gheban, D., Onisor, F., Mitre, I., Manea, A., Trombitas, V., et al. (2019). Histological Change in Soft Tissue Surrounding Titanium Plates after Jaw Surgery. Materials 12, 3205-3208. doi:10.3390/ma12193205

Arrabal, R., Matykina, E., Skeldon, P., Thompson, G. E., and Pardo, A. (2008). Transport of Species during Plasma Electrolytic Oxidation of WE43-T6 Magnesium Alloy. J. Electrochem. Soc. 155, C101. doi:10.1149/1.2823374

Baek, S.-H., Cha, H.-S., Cha, J.-Y., Moon, Y.-S., and Sung, S.-J. (2012). Threedimensional Finite Element Analysis of the Deformation of the Human Mandible: a Preliminary Study from the Perspective of Orthodontic MiniImplant Stability. Korean J. Orthod. 42, 159. doi:10.4041/kjod.2012.42.4.159

Bhatt, V., Chhabra, P., and Dover, M. S. (2005). Removal of Miniplates in Maxillofacial Surgery: A Follow-Up Study. J. Oral Maxill. Surg. 63, 756-760. doi:10.1016/j.joms.2005.02.005

Buijs, G. J., Stegenga, B., and Bos, R. R. M. (2006). Efficacy and Safety of Biodegradable Osteofixation Devices in Oral and Maxillofacial Surgery: A Systematic Review. J. Dent. Res. 85, 980-989. doi:10.1177/154405910608501102

Byun, S. H., Lim, H. K., Cheon, K. H., Lee, S. M., Kim, H. E., and Lee, J. H. (2020). Biodegradable Magnesium alloy (WE43) in Bone-fixation Plate and Screw. J. Biomed. Mater. Res. 108, 2505-2512. doi:10.1002/jbm.b.34582

Champy, M., Loddé, J. P., Schmitt, R., Jaeger, J. H., and Muster, D. (1978). Mandibular Osteosynthesis by Miniature Screwed Plates via a Buccal Approach. J. Maxill. Surg. 6, 14-21. doi:10.1016/S0301-0503(78)80062-9

Claes, L. E., and Heigele, C. A. (1999). Magnitudes of Local Stress and Strain along Bony Surfaces Predict the Course and Type of Fracture Healing. J. Biomech. 32, 255-266. doi:10.1016/S0021-9290(98)00153-5

Demirturk Kocasarac, H., Ustaoglu, G., Bayrak, S., Katkar, R., Geha, H., Deahl, S. T., et al. (2019). Evaluation of Artifacts Generated by Titanium, Zirconium, and Titanium-Zirconium alloy Dental Implants on MRI, CT, and CBCT Images: A Phantom Study. Oral Surg. Oral Med. Oral Pathol. Oral Radiol. 127, 535-544. doi:10.1016/j.oooo.2019.01.074

Friedman, C. D. (2009). "66 Basic Principles of Craniofacial Bone Healing and Repair," in Facial Plastic and Reconstructive Surgery. I. D. Papel, J. L. Frodel, G. R. Holt, W. F. Larrabee, N. E. Nachlas, S. S. Park, et al. (Stuttgart: Georg Thieme Verlag). doi:10.1055/b-0034-73284

Gerlach, K. L., and Schwarz, A. (2002). Bite Forces in Patients after Treatment of Mandibular Angle Fractures with Miniplate Osteosynthesis According to Champy. Int. J. Oral Maxill. Surg. 31, 345-348. doi:10.1054/IJOM.2002.0290

Hachleitner, J., Enzinger, S., Brandtner, C., and Gaggl, A. (2014). The Role of the Titanium Functionally Dynamic Bridging Plate for the Treatment of the Atrophic Mandible Fractures. J. Craniomaxillofac. Surg. 42, 438-442. doi:10. 1016/j.jcms.2013.05.037

\section{SUPPLEMENTARY MATERIAL}

The Supplementary Material for this article can be found online at: https://www.frontiersin.org/articles/10.3389/fbioe.2021.803103/ full\#supplementary-material

Hartjen, P., Wegner, N., Ahmadi, P., Matthies, L., Nada, O., Fuest, S., et al. (2021) Toward Tailoring the Degradation Rate of Magnesium-Based Biomaterials for Various Medical Applications: Assessing Corrosion, Cytocompatibility and Immunological Effects. Ijms 22, 971. doi:10.3390/ijms22020971

Hijazi, L., Hejazi, W., Darwich, M. A., and Darwich, K. (2016). Finite Element Analysis of Stress Distribution on the Mandible and Condylar Fracture Osteosynthesis during Various Clenching Tasks. Oral Maxillofac. Surg. 20, 359-367. doi:10.1007/s10006-016-0573-2

Imwinkelried, T., Beck, S., and Schaller, B. (2020). Pre-clinical Testing of Human Size Magnesium Implants in Miniature Pigs: Implant Degradation and Bone Fracture Healing at Multiple Implantation Sites. Mater. Sci. Eng. C 108, 110389. doi:10.1016/j.msec.2019.110389

Jung, B. T., Kim, W. H., Park, B., Lee, J.-H., Kim, B., and Lee, J.-H. (2020). Biomechanical Evaluation of Unilateral Subcondylar Fracture of the Mandible on the Varying Materials: A Finite Element Analysis. PLoS One 15, e0240352. doi:10.1371/journal.pone.0240352

Katou, F., Andoh, N., Motegi, K., and Nagura, H. (1996). Immuno-inflammatory Responses in the Tissue Adjacent to Titanium Miniplates Used in the Treatment of Mandibular Fractures. J. Craniomaxillofac. Surg. 24, 155-162. doi:10.1016/S1010-5182(96)80049-7

Kaur, P., Kaura, S., Bahl, R., Bansal, S., and Sangha, P. (2018). Retrospective Study of Facial Fractures. Ann. Maxillofac. Surg. 8, 78-82. (Mumbai, India: Medknow Publications and Media Pvt. Ltd.). doi:10.4103/ams.ams_73_17

Kimsal, J., Baack, B., Candelaria, L., Khraishi, T., and Lovald, S. (2011). Biomechanical Analysis of Mandibular Angle Fractures. J. Oral Maxill. Surg. 69, 3010-3014. doi:10.1016/j.joms.2010.12.042

Korioth, T. W. P., Romilly, D. P., and Hannam, A. G. (1992). Three-dimensional Finite Element Stress Analysis of the Dentate Human Mandible. Am. J. Phys. Anthropol. 88, 69-96. doi:10.1002/ajpa.1330880107

Lakatos, É., Magyar, L., and Bojtár, I. (2014). Material Properties of the Mandibular Trabecular Bone. J. Med. Eng. 2014, 1-7. doi:10.1155/2014/470539

Lee, H.-B., Oh, J.-S., Kim, S.-G., Kim, H.-K., Moon, S.-Y., Kim, Y.-K., et al. (2010). Comparison of Titanium and Biodegradable Miniplates for Fixation of Mandibular Fractures. J. Oral Maxill. Surg. 68, 2065-2069. doi:10.1016/j. joms.2009.08.004

Leonhardt, H., Franke, A., McLeod, N. M. H., Lauer, G., and Nowak, A. (2017). Fixation of Fractures of the Condylar Head of the Mandible with a New Magnesium-alloy Biodegradable Cannulated Headless Bone Screw. Br. J. Oral Maxill. Surg. 55, 623-625. doi:10.1016/j.bjoms.2017.04.007

Leonhardt, H., Ziegler, A., Lauer, G., and Franke, A. (2021). Osteosynthesis of the Mandibular Condyle with Magnesium-Based Biodegradable Headless Compression Screws Show Good Clinical Results during a 1-Year FollowUp Period. J. Oral Maxill. Surg. 79, 637-643. doi:10.1016/j.joms.2020. 02.025

Levorova, J., Duskova, J., Drahos, M., Vrbova, R., Vojtech, D., Kubasek, J., et al. (2018). In Vivo study on Biodegradable Magnesium Alloys: Bone Healing Around WE43 Screws. J. Biomater. Appl. 32, 886-895. doi:10.1177/ 0885328217743321

Lovald, S. T., Wagner, J. D., and Baack, B. (2009). Biomechanical Optimization of Bone Plates Used in Rigid Fixation of Mandibular Fractures. J. Oral Maxill. Surg. 67, 973-985. doi:10.1016/j.joms.2008.12.032

MacLeod, A. R., Pankaj, P., and Simpson, A. H. R. W. (2012). Does Screw-Bone Interface Modelling Matter in Finite Element Analyses? J. Biomech. 45, 1712-1716. doi:10.1016/j.jbiomech.2012.04.008

Marukawa, E., Tamai, M., Takahashi, Y., Hatakeyama, I., Sato, M., Higuchi, Y., et al. (2016). Comparison of Magnesium Alloys and Poly-L-Lactide Screws as Degradable Implants in a Canine Fracture Model. J. Biomed. Mater. Res. 104, 1282-1289. doi:10.1002/jbm.b.33470

Matthew, I. R., and Frame, J. W. (1999). Policy of Consultant Oral and Maxillofacial Surgeons towards Removal of Miniplate Components after Jaw 
Fracture Fixation: Pilot Study. Br. J. Oral Maxill. Surg. 37, 110-112. doi:10.1054/ bjom.1997.0084

MatWeb L. L. C. (2021). Material Property Data. Available at: www.matweb.com (Accessed September 28, 2021).

Moe, K. S., and Weisman, R. A. (2001). Resorbable Fixation in Facial Plastic and Head and Neck Reconstructive Surgery: An Initial Report on Polylactic Acid Implants. The Laryngoscope 111, 1697-1701. doi:10.1097/00005537200110000-00005

Naujokat, H., Seitz, J.-M., Açil, Y., Damm, T., Möller, I., Gülses, A., et al. (2017). Osteosynthesis of a Cranio-Osteoplasty with a Biodegradable Magnesium Plate System in Miniature Pigs. Acta Biomater. 62, 434-445. doi:10.1016/j.actbio. 2017.08.031

Nelson, G. J. (1986). Three Dimensional Computer Modeling of Human Mandibular Biomechanics. MSc Dissertation. Vancouver, Canada: University of British Columbia. doi:10.14288/1.0096998

On, S.-W., Cho, S.-W., Byun, S.-H., and Yang, B.-E. (2020). Bioabsorbable Osteofixation Materials for Maxillofacial Bone Surgery: A Review on Polymers and Magnesium-Based Materials. Biomedicines 8, 300. doi:10. 3390/biomedicines 8090300

Orassi, V., Duda, G. N., Heiland, M., Fischer, H., Rendenbach, C., and Checa, S. (2021). Biomechanical Assessment of the Validity of Sheep as a Preclinical Model for Testing Mandibular Fracture Fixation Devices. Front. Bioeng. Biotechnol. 9. doi:10.3389/fbioe.2021.672176

Park, B., Jung, B. T., Kim, W. H., Lee, J.-H., Kim, B., and Lee, J.-H. (2020). The Stability of Hydroxyapatite/poly-L-Lactide Fixation for Unilateral Angle Fracture of the Mandible Assessed Using a Finite Element Analysis Model. Materials 13, 228. doi:10.3390/ma13010228

Pepelnjak, T., Karimi, A., Maček, A., and Mole, N. (2020). Altering the Elastic Properties of 3D Printed Poly-Lactic Acid (Pla) Parts by Compressive Cyclic Loading. Materials 13, 4456. doi:10.3390/ma13194456

Radzi, S., Cowin, G., Robinson, M., Pratap, J., Volp, A., Schuetz, M. A., et al. (2014). Metal Artifacts from Titanium and Steel Screws in CT, 1.5T and 3T MR Images of the Tibial Pilon: a Quantitative Assessment in 3D. Quant. Imaging Med. Surg. 4, 163-172. doi:10.3978/j.issn.2223-4292.2014.03.06

Rendenbach, C., Schoellchen, M., Bueschel, J., Gauer, T., Sedlacik, J., Kutzner, D., et al. (2018). Evaluation and Reduction of Magnetic Resonance Imaging Artefacts Induced by Distinct Plates for Osseous Fixation: An In Vitro Study @ 3 T. Dentomaxillofacial Radiol. 47, 20170361. doi:10.1259/dmfr. 20170361

Rendenbach, C., Fischer, H., Kopp, A., Schmidt-Bleek, K., Kreiker, H., Stumpp, S., et al. (2021). Improved In Vivo Osseointegration and Degradation Behavior of PEO Surface-Modified WE43 Magnesium Plates and Screws after 6 and 12 Months. Mater. Sci. Eng. C 129, 112380. doi:10.1016/j.msec.2021.112380

Riviş, M., Roi, C., Roi, A., Nica, D., Văleanu, A., and Rusu, L.-C. (2020). The Implications of Titanium Alloys Applied in Maxillofacial Osteosynthesis. Appl. Sci. 10, 3203. doi:10.3390/app10093203

Rosa, J. H., Villanueva, N. L., Sanati-Mehrizy, P., Factor, S. H., and Taub, P. J. (2016). Review of Maxillofacial Hardware Complications and Indications for Salvage. Craniomaxillofacial Trauma \& Reconstruction 9, 134-140. doi:10. 1055/s-0035-1570074

Schaller, B., Saulacic, N., Imwinkelried, T., Beck, S., Liu, E. W. Y., Gralla, J., et al. (2016). In Vivo degradation of Magnesium Plate/screw Osteosynthesis Implant Systems: Soft and Hard Tissue Response in a Calvarial Model in Miniature Pigs. J. Craniomaxillofac. Surg. 44, 309-317. doi:10.1016/j.jcms.2015.12.009

Schwartz-Dabney, C. L., and Dechow, P. C. (2003). Variations in Cortical Material Properties throughout the Human Dentate Mandible. Am. J. Phys. Anthropol. 120, 252-277. doi:10.1002/ajpa.10121

Shetty, V., Caputo, A. A., and Kelso, I. (1997). Torsion-axial Force Characteristics of SR-PLLA Screws. J. Craniomaxillofac. Surg. 25, 19-23. doi:10.1016/S10105182(97)80020-0

Simchen, F., Sieber, M., Kopp, A., and Lampke, T. (2020). Introduction to Plasma Electrolytic Oxidation-An Overview of the Process and Applications. Coatings 10, 628. doi:10.3390/coatings 10070628

Sukegawa, S., Kanno, T., Nagano, D., Shibata, A., Sukegawa-Takahashi, Y., and Furuki, Y. (2016). The Clinical Feasibility of Newly Developed Thin Flat-type
Bioresorbable Osteosynthesis Devices for the Internal Fixation of Zygomatic Fractures. J. Craniofac. Surg. 27, 2124-2129. doi:10.1097/SCS. 0000000000003147

Sukegawa, S., Masui, M., Sukegawa-Takahashi, Y., Nakano, K., Takabatake, K., Kawai, H., et al. (2020). Maxillofacial Trauma Surgery Patients with Titanium Osteosynthesis Miniplates. J. Craniofac. Surg. 31, 1338-1342. Publish Ahead of Print. doi:10.1097/SCS.0000000000006352

Suuronen, R., Pohjonen, T., Hietanen, J., and Lindqvist, C. (1998). A 5-year In Vitro and In Vivo Study of the Biodegradation of Polylactide Plates. J. Oral Maxill. Surg. 56, 604-614. doi:10.1016/S0278-2391(98)90461-X

Tams, J., Otten, B., Loon, J.-P. v., and Bos, R. R. M. (1999). A Computer Study of Fracture Mobility and Strain on Biodegradable Plates Used for Fixation of Mandibular Fractures. J. Oral Maxill. Surg. 57, 973-981. doi:10.1016/S02782391(99)90020-4

Torres, J., Cotelo, J., Karl, J., and Gordon, A. P. (2015). Mechanical Property Optimization of FDM PLA in Shear with Multiple Objectives. JOM 67, 1183-1193. doi:10.1007/s11837-015-1367-y

Torroni, A., Witek, L., Fahliogullari, H. P., Bortoli, J. P., Ibrahim, A., Hacquebord, J., et al. (2021). WE43 and WE43-T5 Mg Alloys Screws Tested In-Vitro Cellular Adhesion and Differentiation Assay and In-Vivo Histomorphologic Analysis in an Ovine Model. J. Biomater. Appl. 35, 901-911. doi:10.1177/ 0885328220956788

Van Bakelen, N. B., Buijs, G. J., Jansma, J., de Visscher, J. G. A. M., Hoppenreijs, T. J. M., Bergsma, J. E., et al. (2013). Comparison of Biodegradable and Titanium Fixation Systems in Maxillofacial Surgery. J. Dent. Res. 92, 1100-1105. doi:10. 1177/0022034513508953

Viljanen, J., Kinnunen, J., Bondestam, S., Majola, A., Rokkanen, P., and Törmälä, P. (1995). Bone Changes after Experimental Osteotomies Fixed with Absorbable Self-Reinforced Poly-L-Lactide Screws or Metallic Screws Studied by plain Radiographs, Quantitative Computed Tomography and Magnetic Resonance Imaging. Biomaterials 16, 1353-1358. doi:10.1016/0142-9612(95)91052-Z

Wang, Z., Wang, Y., Ito, Y., Zhang, P., and Chen, X. (2016). A Comparative Study on the In Vivo Degradation of poly(L-Lactide) Based Composite Implants for Bone Fracture Fixation. Sci. Rep. 6, 1-12. doi:10.1038/srep20770

Wang, C., Zhang, G., Li, Z., Zeng, X., Xu, Y., Zhao, S., et al. (2019). Tribological Behavior of Ti-6Al-4V against Cortical Bone in Different Biolubricants. J. Mech. Behav. Biomed. Mater. 90, 460-471. doi:10.1016/j.jmbbm.2018.10.031

Witte, F., Kaese, V., Haferkamp, H., Switzer, E., Meyer-Lindenberg, A., Wirth, C. J., et al. (2005). In Vivo corrosion of Four Magnesium Alloys and the Associated Bone Response. Biomaterials 26, 3557-3563. doi:10.1016/j.biomaterials.2004. 09.049

Witte, F. (2010). The History of Biodegradable Magnesium Implants: A Review 2 . Acta Biomater. 6, 1680-1692. doi:10.1016/j.actbio.2010.02.028

Yerit, K. C., Hainich, S., Turhani, D., Klug, C., Wittwer, G., Ockher, M., et al. (2005). Stability of Biodegradable Implants in Treatment of Mandibular Fractures. Plast. Reconstr. Surg. 115, 1863-1870. doi:10.1097/01.PRS. 0000165075.51898.6F

Conflict of Interest: The authors declare that the research was conducted in the absence of any commercial or financial relationships that could be construed as a potential conflict of interest.

Publisher's Note: All claims expressed in this article are solely those of the authors and do not necessarily represent those of their affiliated organizations or those of the publisher, the editors, and the reviewers. Any product that may be evaluated in this article or claim that may be made by its manufacturer is not guaranteed or endorsed by the publisher.

Copyright $\odot 2022$ Orassi, Fischer, Duda, Heiland, Checa and Rendenbach. This is an open-access article distributed under the terms of the Creative Commons Attribution License (CC BY). The use, distribution or reproduction in other forums is permitted, provided the original author(s) and the copyright owner(s) are credited and that the original publication in this journal is cited, in accordance with accepted academic practice. No use, distribution or reproduction is permitted which does not comply with these terms. 